\title{
Natural convection in partially heated square cavity
}

\author{
SaraTabet*, Ahmed Zineddine Dellil**, Abbès Azzi*** \\ *Institut de Maintenance et de Sécurité Industrielle, IMSI, Université dOran, L.A.H.N., USTO, Oran, Algeria, \\ E-mail: tabetsara473@yahoo.fr \\ **Institut de Maintenance et de Sécurité Industrielle, IMSI, Université dOran, L.A.H.N., USTO, Oran, Algeria, \\ E-mail: sdellil@yahoo.fr \\ ***LAHN, USTO, Oran, Algeria \\ cross $^{\text {ref }}$ http://dx.doi.org/10.5755/j01.mech.22.2.12215
}

\section{Nomenclature}

$C_{\mu}$ - empirical constant in turbulence model; $g$ - gravitational acceleration; $k$ - turbulent kinetic energy; $l_{\mu}, l_{\varepsilon}$ - turbulence length scale; $L$ - width of the cavity; $N u(y)$ - local Nusselt number; $P r$ - Prandtl number; $T$-temperature; $u$ - fluid velocity component in $x$-direction; $u^{\prime} v^{\prime}$ - Reynolds stress; $\overline{u_{i}^{\prime} T^{\prime}}$ - turbulent heat flux; $v$ - fluid velocity component in $y$-direction; $V_{o}$ - buoyancy velocity $=\sqrt{g \beta H \Delta T}$; $w$ - fluid velocity component in $z$-direction; $x, y, z$-Cartesian coordinates; $X, Y, Z$-dimensionless co-ordinates; $\Delta T$-temperature difference $\Delta T=T_{h}-T_{c}, \quad R a$-Rayleigh number

greek letters-

$\alpha$-thermal diffusivity; $\beta$-thermal expansion coefficient; $\varepsilon$ - turbulent energy dissipation rate; $\mu$-dynamic viscosity; $v$ - kinematic viscosity; $\rho$ - fluid density

\section{Introduction}

The Study of the heat transfers by natural convection in the square cavities aroused an essential interest during these last decades. This interest is dictated by the role played by such configuration in various domains: The cooling of electronic components, air conditioning, the heat exchanges, the thermal power plants, the insulation systems, etc. Several works were realized numerically, others experimentally. The prediction of the behavior of these flows requires the thorough knowledge of the physical phenomena which occur in this closed cavity. The natural convection in heated cavities differentially to the numbers of Rayleigh until approximately $10^{9}$ was experimentally examined [1-8]. The steady laminary flow of these flows is studied well. However, in most of the applications, the flows are unsteady and turbulent. The current researches are Numerical [1-2] and experimental [3-4]. These studies give a big and useful database for the validation of numerical simulations. During the 90s, a difference was observed between experimental results and 2D of the DNS (Direct Numerical Simulations) [9].

In this context, many numerical studies were made by using the Direct Numerical Simulation [9], and Large Eddy Simulation [10-11] for the 3D and for the turbulent flows.

Numerous authors [6-7] studied numerically the laminar natural convection in totally opened cavities. Penot [2] analyzed the same problem for Grashof numbers going from $10^{3}$ to $10^{5}$. Chan and Yours [15] studied the natural convection in totally opened square cavities, having two walls Horizontal adiabatic and the other vertical wall. On one year later, the same authors [16], by realizing another study on other cavities and by comparing it with the square cavities, found that the cavity, studied by [15], gave satisfactory results specially to large Rayleigh numbers. Miyamoto and al. [13] studied the convection in square cavities partially and totally opened, among which three walls were isothermal, in different angles. Bilgen and Oztop [14] studied the natural laminar convection in the oblique partially opened square cavities, of which the opposite wall in the opening was isothermal and two others were adiabatic. They studied the influence of the position size and of the opening, the number of $\mathrm{Ra}\left[10^{3}-10^{6}\right]$; and of inclination of the cavity.

Azzi and al. [20] studied the laminar and turbulent natural convection in the internal of a square heated cavity differentially. The results belonged in good agreement with those of Ampofo and Karayiannis [18] for the turbulent part, and to those of De Vahl Davis [19] for the laminar part. Ampofo [18], realized an experiment on the square cavities filled with air and partitionnées on the side of the hot wall, The obtained results were very good, and are used as a benchmark for the validation of the codes of the Computational Fluid Domain. The objective of our study is to test the behavior of Numerical program CAVITY by comparing the results of the heated cavity differentially (De Vahl Davis [19]). In the second stage the code is used to see the effect of the heated partially wall on the structure of the flow and the thermal transfer.

\section{Models and boundary conditions}

\subsection{Mathematical model and numerical method}

Incompressible fluid flows are governed by the Navier - Stokes equations. These equations relate the speed and the pressure in every point of the flow. Four unknown functions must be determined: the three components of the vector speed and the pressure. This paragraph is devoted to the presentation of the results of the tested case; laminar natural convection in a square differentially heated cavity.

The fluid is the air $(\operatorname{Pr}=0.7)$, both top and bottom walls are adiabatic, while the right and left walls are maintained at constant temperatures of the order of 10 and $50^{\circ} \mathrm{C}$ respectively. The flow and the heat transfer are represented by the stream lines and the isotherms.

CAVITY is a numerical house solver developed in the Laboratory of Naval Aero Hydrodynamics (USTO, 
Algeria), based on the Fortran and using the finite difference method to solve the Naviers Stokes equations. The code uses the discrete formulation Psi-Omega in the second order, on structured 2D numerical grids. The resolution of the algebraic system of equations is made by a successive method of relaxation. The current version is limited to two-dimensional incompressible fluids in laminar regime. The buoyancy effect (natural convection) is supported through a source term incorporated in the momentum equations in agreement with the Boussinesq approximation.

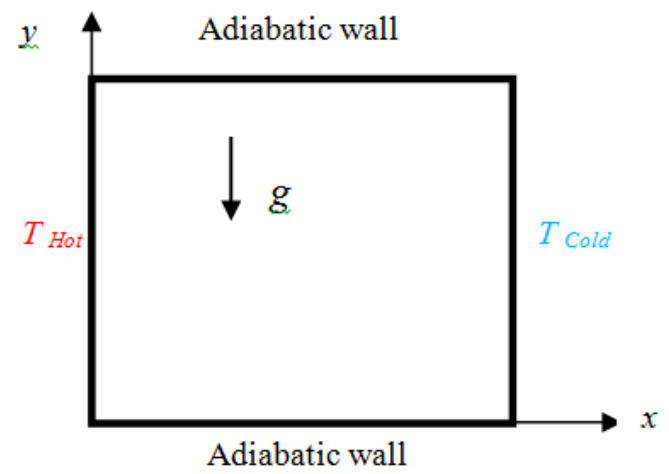

Fig. 1 Calculation Domain and boundary conditions

\subsection{Optimization of the mesh}

The optimization of the mesh consists on choosing the one who converges best giving good results, and who consumes the least possible of time CPU. For this, we conducted a simulation of the differentially heated cavity for a Rayleigh number equal to $10^{4}$. We used four computing grids ranging from single to double, and we traced the evolution of the Nusselt number on the heated wall. The grids have the following sizes: 20.20, 50.50, 100.100, and 200.200. According to the Fig. 2, which represents the evolution of the Nusselt number, it is clear that the 100.100 grid produces results appreciably the same as that of the upper grid with less computing time. This grid will be adopted for the rest of the calculations in this study.

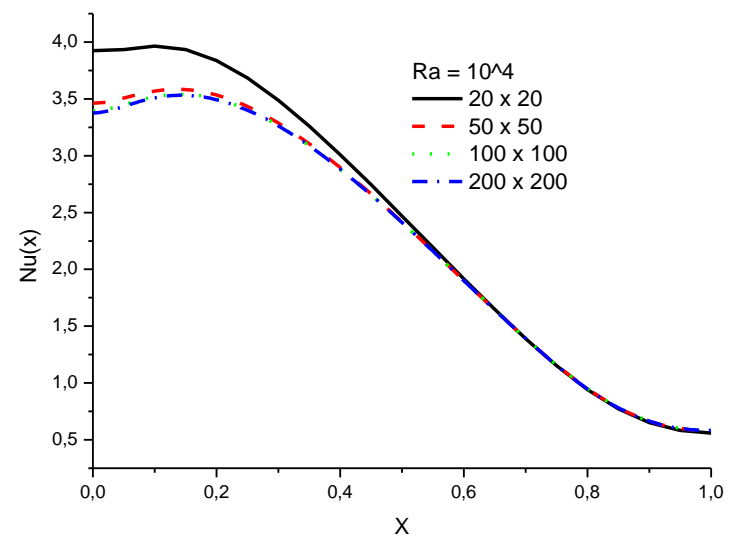

Fig. 2 Evolution of the Nusselt number on the heated wall, of the differentially heated cavity. Comparison of the results of four computing grids

\section{Validation}

For the validation of the numerical program, we conducted a study of differentially heated cavity at Ray- leigh numbers ranging from $10^{4}$ to $10^{6}$. Table 1 shows the comparison of the average Nusselt number by comparing the results of the present study with those of De Vahl Davis [19]. Analysis of the results shows that the calculations of this study are very satisfactory compared to this test cases (Nusselt). As an example, the Fig. 3 shows the structure of the thermal field through the plot of the isotherms of the cavity at Rayleigh equal to $10^{4}$ and $10^{6}$. The cases of higher Rayleigh numbers show more pronounced temperature stratification.

Table 1

Validation of the average Nusselt number

\begin{tabular}{|c|c|c|c|c|}
\hline & $10^{4}$ & $10^{5}$ & $10^{6}$ & $10^{7}$ \\
\hline Vahl Davis & 2.243 & 4.52 & 8.8 & 16.4 \\
\hline The present study & 2.246 & 4.405 & 8.157 & 15.780 \\
\hline
\end{tabular}

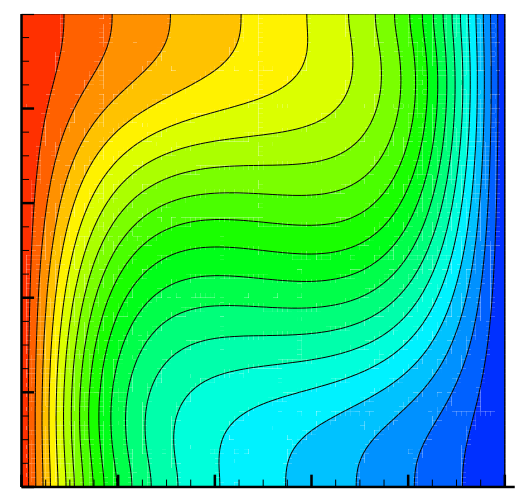

$$
R a=10^{4}
$$

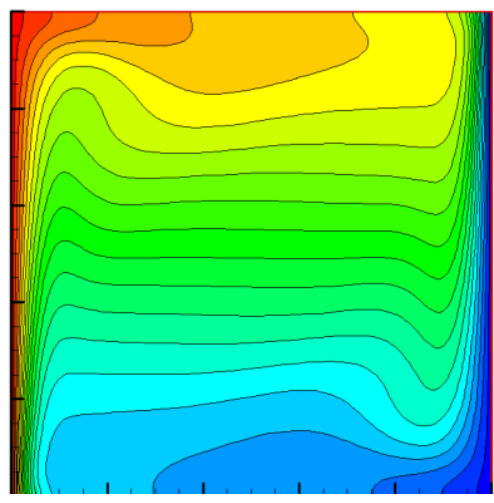

$$
R a=10^{6}
$$

Fig. 3 Isotherms of the differentially heated cavity

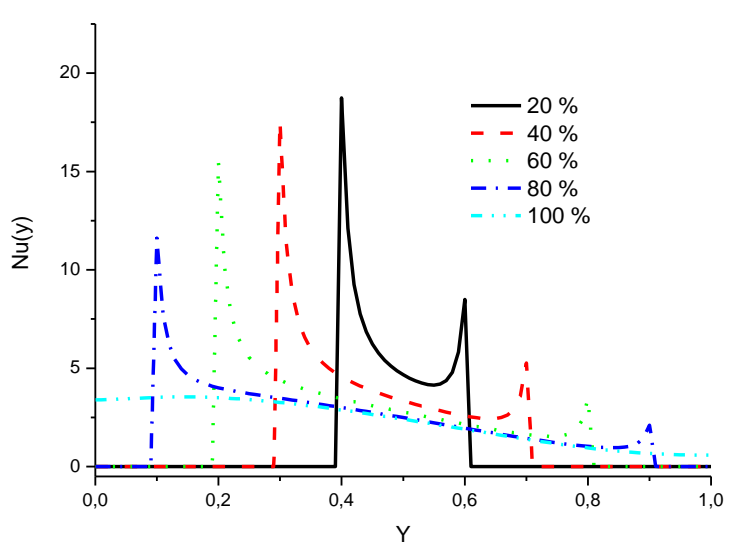

Fig. 4 Evolution of the local Nusselt number along the heated face according to the percentage heating, the case of $R a=10^{4}$ 


\section{Results and discussions}

\subsection{Laminar flow}

The Nusselt number is defined as:

$$
N u(y)=\frac{L}{\left(T_{h}-T_{c}\right)} \frac{\partial T}{\partial x},(x=0) .
$$

And the averaged Nusselt number as:

$$
\overline{N u}=\int_{y=0}^{y=L} N u(y) d y .
$$

After validation and review of results obtained for the classical differentially heated cavity, we conducted a parametric study by changing the portion of the heated

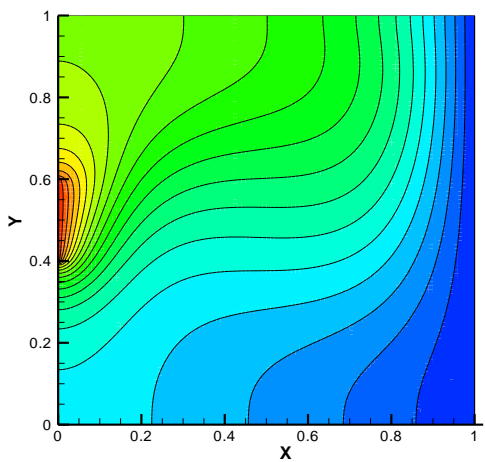

$20 \%$

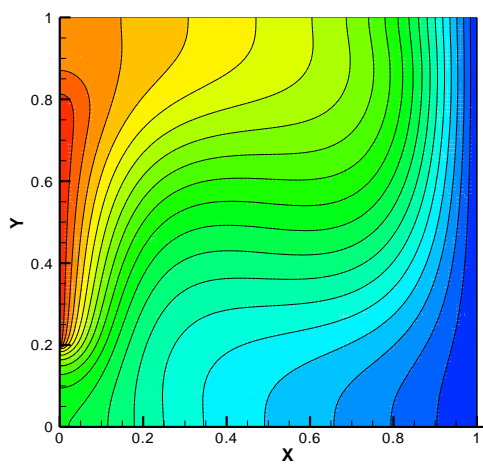

$60 \%$ wall which will be $20,40,60,80$ and $100 \%$. The purpose is to see the effect of the partial heating on the structure of flow and the heat transfer.

The calculation is conducted for the Rayleigh number equal to $10^{4}$, and shows that a large temperature gradient at the bottom of the cavity and which decreases by going upward. This behavior is in agreement with the visual examination which shows that the thermal boundary layer is thin at the bottom of the cavity and thicker upward. By applying a partial heating, we note, by all the cases, the appearance of peaks on either side of the heating zone. This behavior is in agreement with the development of the thermal boundary layer at the borders of the heated area. Another finding confirms that the level of the local Nusselt number values is higher for the low heating portions than for the large ones. The Fig. 5 shows the plot of isotherms for the case $R=10^{4}$ and for the different partial heating levels.

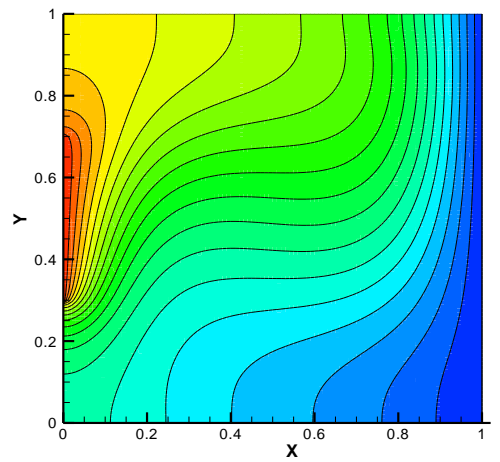

$40 \%$

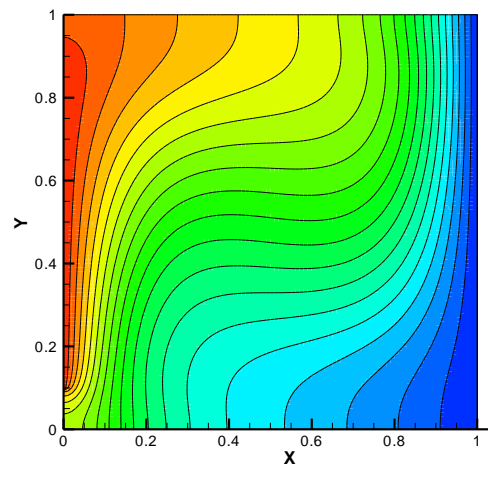

$80 \%$

Fig. 5 Isotherms for different cases of partial heating at $R a=10^{4}$

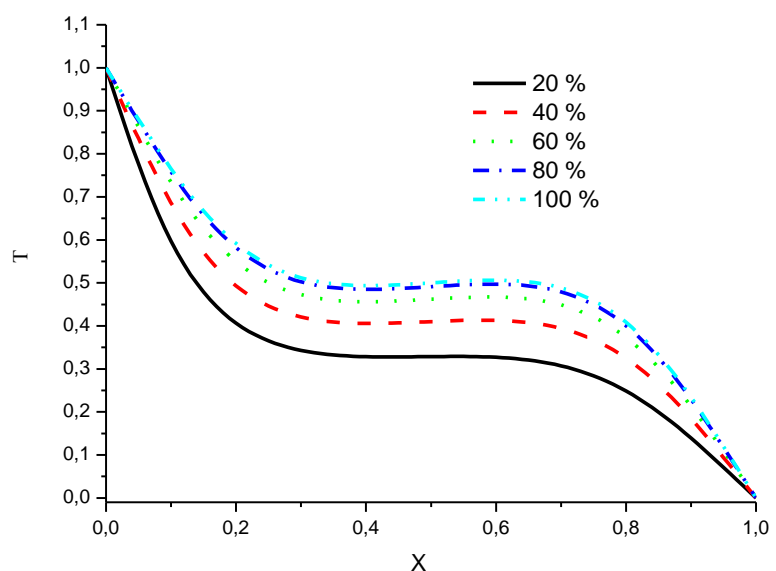

Fig. 6 Changes of temperature on a horizontal line at midheight of the cavity
In this case at low Rayleigh number, we note the small effect of partial heating on the thermal field structure with a slight deformation of the isothermal lines marrying and enveloping the heated portion. The right zone corresponding to the cold wall remains substantially unchanged.

The Fig. 6 shows the evolution of the temperature on a horizontal line situated exactly in the mid-height of the cavity. The plot shows a lower level of temperature in the center of the cavity for the case of the lower heating $(20 \%)$. This level increases with the increase of the partial heating with almost little difference between the cases 80 and $100 \%$. Table 2 shows the values of the average Nusselt number for the case $R a=10^{4}$ and for the different partial heating levels. 
Table 2 the average Nusselt number according to the level of the

Effect of the partial heating on the average Nusselt number, $R a=10^{4}$

\begin{tabular}{|c|c|c|c|c|c|}
\hline heating & $20 \%$ & $40 \%$ & $60 \%$ & $80 \%$ & $100 \%$ \\
\hline Averaged $\mathrm{Nu}$ & 1.408 & 1.807 & 2.057 & 2.195 & 2.246 \\
\hline
\end{tabular}

The values of the average Nusselt attest the low thermal transfer level for the cases with low partial heating with an increase to as the percentage of the heating increases. The value of the low case $(20 \%)$ is almost of half of that of the complete heating $(100 \%)$. In order to complete the investigation of the laminar case, a similar study was conducted for a Rayleigh number slightly higher but always in the laminar zone. Table 3 shows the evolution of
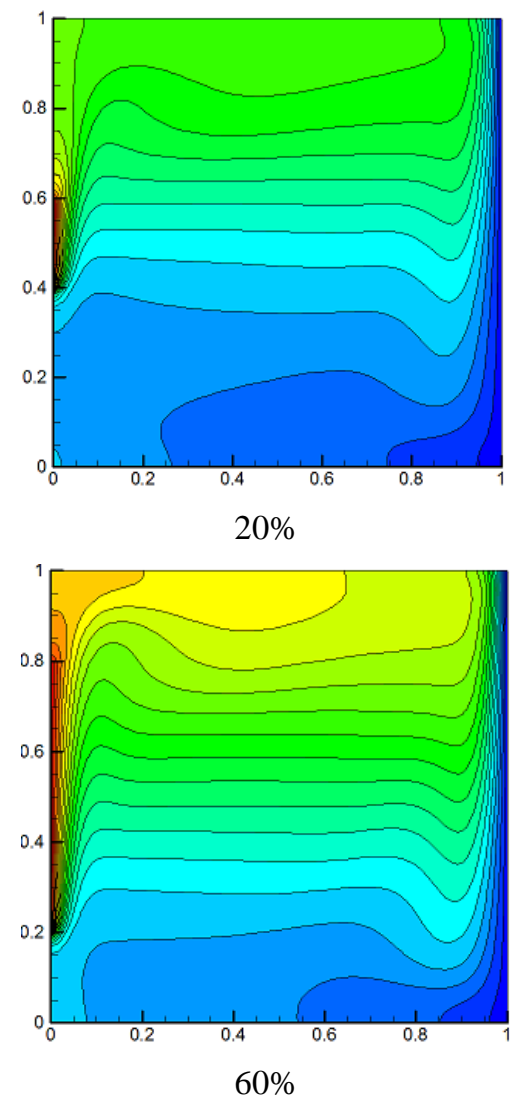

partial heating for the case $R a=10^{6}$. Here we see the same proportional dependence between the average Nusselt and the level of the heating with a value of the cases (20\%), almost of half of the cases (100\%).

Table 3

Effect of the partial heating on the average Nusselt number, $R a=10^{6}$

\begin{tabular}{|c|c|c|c|c|c|}
\hline heating & $20 \%$ & $40 \%$ & $60 \%$ & $80 \%$ & $100 \%$ \\
\hline Averaged $\mathrm{Nu}$ & 4.165 & 5.866 & 7.056 & 7.829 & 8.157 \\
\hline
\end{tabular}

The structure of the thermal field for this case is shown on the Fig. 7.
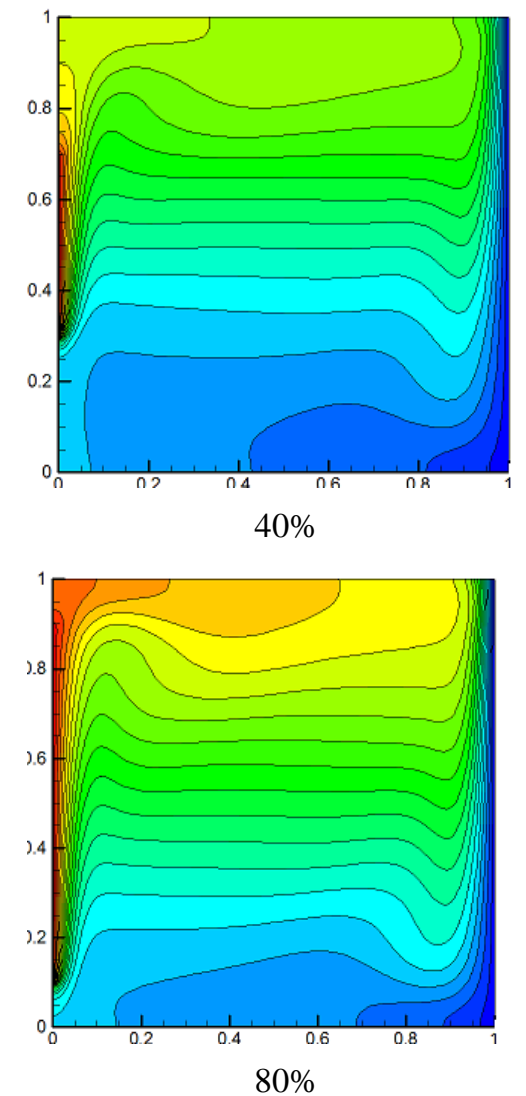

Fig. 7 Isotherms for different cases of partial heating at $\mathrm{Ra}=10^{6}$

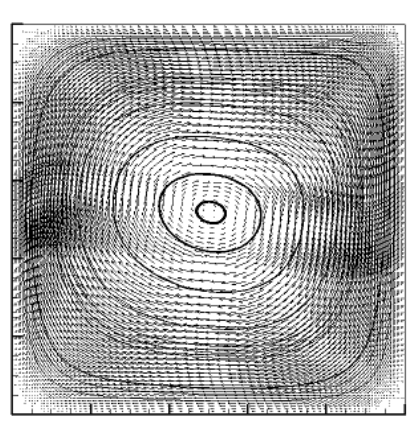

$20 \%$

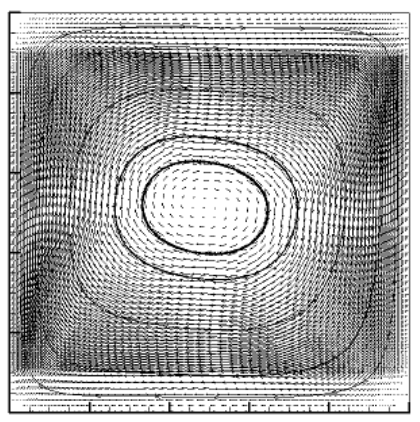

$40 \%$

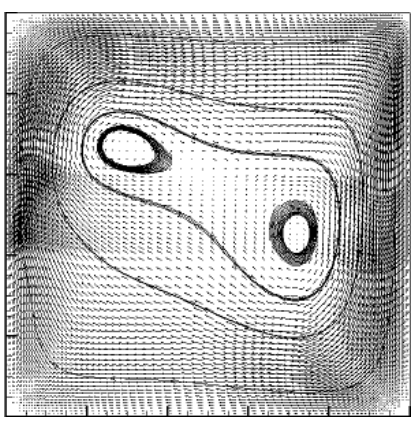

$60 \%$

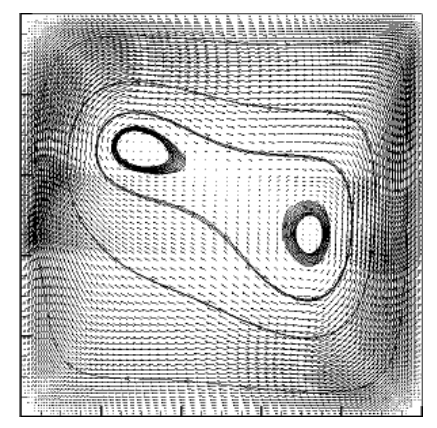

$80 \%$

Fig. 8 The streamlines and the velocity vectors for two partial heating levels and for two Rayleigh number. $R a=10^{4}$ 
For this case at Rayleigh relatively high and characterized by a stratification of the temperature, we notice a rather considerable change caused by the partial heating. It is clear from this figure that the lower half of the cavity is immersed in much lower temperature than the upper half. This phenomenon can be explained by the physics of the natural convection that stipulate that the air particles in the vicinity of the hot wall migrate upward by transporting with them the heat given up by the hot wall. The lower part of the cavity, surrounded by the adiabatic walls, and with the cold wall remains in an atmosphere colder than that of the upper part. To complete the presentation, Figure 8 shows the streamlines as well as the velocity vectors of two partial heating levels (20 and $80 \%)$ and for the two Rayleigh numbers studied $\left(R a=10^{4}\right.$ and $\left.10^{6}\right)$.

\section{Conclusion}

A numerical investigation of the laminar natural convection inside a differentially heated square cavity was the subject of this article. For this laminar flow the terms of the buoyancy are modeled by the well-known Boussinesq approximation. The results of the laminar flow calculation show that the present study provides very well the solutions of the test case. The effect of the partial heating applied to the hot wall was examined for a range of Rayleigh number going from $10^{4}$ to $10^{6}$. The heating was applied at 20,40,60,80 and $100 \%$ of the hot wall. The results of this investigation show that the partial heating has an important influence on the structure of the flow and on the heat transfer inside the cavity. This effect is even more intense than the Rayleigh number is important.

\section{References}

1. Le Quere, P. 1987. Etude de la transition à l'instationnarité des écoulements de la convection naturelle en cavité vertical diffèrentiellement chauffée par methodes spectrales Chebyshev, Thèse de doctorat d'état, Université de Poitiers, France.

2. Penot, F. 1982. Numerical calculation of twodimensional natural convection in isothermal open cavities, Numer. Heat Transfer 5 : 421-437. http://dx.doi.org/10.1080/10407788208913457.

3. Ndame, A. 1992. Etude expérimentale de la con- vection naturelle en cavité de l'état stationnaire auchaos, Thèse de doctorat Université de Poitiers, France.

4. Mergui, S.; Penot, F. 1996. Convection naturelle en cavité carrée différentiellement chauffée: investigation expérimentale à $\mathrm{Ra}=1,6910^{9}$. Int. J Heat MassTransf 39(3): 563-574.

http://dx.doi.org/10.1016/0017-9310(95)00133-T.

5. Penot, F.; Ndame, A.; Le Quéré, P. 1990. Investigation of the route the turbulence in avertical differrencially heated cavity, proceeding of the 9th International Heat Transfer Conference, Jerusalem 2: 417-422.

6. Xin, S; Le Quéré, P. 2006. Natural convectionflows in air-filled differentially heated cavities with adiabatic horizontal walls, Numer Heat Transfer, Part A 50(5): 437-66. http://dx.doi.org/10.1080/10407780600605039.

7. Tian, Y.S.; Karayiannis, T.G. 2000. Low turbulence natural convection in an air filled square cavity. Part I: the thermal and fluid flow fields, Int $\mathrm{J}$ Heat Mass
Transf 43: 849-866.

http://dx.doi.org/10.1016/S0017-9310(99)00199-4.

8. Tian, Y.S.; Karayiannis, T.G. 2000. Low turbulence natural convection in an air filled square cavityPart II: the turbulence quantities, Int $\mathbf{J}$ Heat Mass Transf 43: 867-884. http://dx.doi.org/10.1016/S0017-9310(99)00200-8.

9. Xin, S; Le Quéré, P. 1995. Direct numerical simulations of two-dimensional chaotic natural convection in a differentially heated cavity of aspect ratio 4, J Fluid Mech 304: 87-118.

http://dx.doi.org/10.1017/S0022112095004356.

10. Trias, F.X.; Soria, M.; Olivia, A.; Perez-Segarra, C.D. 2007. Direct numerical simulations of two- and three-dimensional turbulent natural convection flows in a differentially heated cavity of aspect ratio 4, J Fluid Mech 586: 259-293. http://dx.doi.org/10.1017/S0022112007006908.

11. Peng, S.; Davidson. L. 2001. Large eddy simulation for turbulent buoyant flow in a contained cavity, Int $\mathbf{J}$. Heat Mass Transf 22: 323-331.

12. Xin, S.; Salat, J.; Joubert, P.; Sergent, A.; Le Quéré, P.; Penot, F. 2006. 3D numerical simulations of Turbulent natural convection in an air-filleddifferentially heated cavity, In Proceedings of the 13th International Heat Transfer Conference (IHTC, Sydney, Australia).

13. Miyamoto, M.; Kuehn, T.H.; Goldstein, J.; Katoh, Y. 1989. Two dimensional laminar natural convection heat transfer from a fully or partially open square cavity, Numer. Heat Transfer A15: 411-430. http://dx.doi.org/10.1080/10407788908944696.

14. Bilgen, E.; Oztop, H. 2005. Natural convection heat transfer in partially open inclined square cavities, International Journal of Heat andMass Transfer 48: 1470-1479.

15. Y.L. Chan, Y.L.; Tien, C.L. 1985. A numerical study of two-dimensional laminar natural convection in shal low open cavities, International Journal of Heat and Mass Transfer 28: 603-612. http://dx.doi.org/10.1016/0017-9310(85)90182-6.

16. Chan, Y.L.; Tien, C.L.1986. Laminar natural convection in shallow open cavities, Journal of Heat Transfer 108: 305-309. http://dx.doi.org/10.1115/1.3246920.

17.Skok, H.; Ramadhyani, S.; Choenhals, R.J. 1991. Natural convection in side-facing open cavity, International Journal of Heat and Fluid Flow 12: 36-45. http://dx.doi.org/10.1016/0142-727X(91)90006-H.

18. Ampofo, F.; Karayiannis, T.G. 2003. Experimental cas test data for turbulent natural convection in an air filled square cavity, Int. J. Heat Mass Transfer 46: 3551-3735. http://dx.doi.org/10.1016/S0017-9310(03)00147-9.

19. G. De Vahl Davis 1983. Natural convection of air in a square cavity: A benchmark numerical solution, Int. J. Nummer. Methods Fluids 3 : 249-264. http://dx.doi.org/10.1002/fld.1650030305.

20. Azzi, A.; Dellil, A.Z.; Bouchouicha, M.S., Nemdili, F. 2013. Prediction numerique du champ thermo dynamique laminaire et turbulent a l'interieure d'une cavite carree differentiellement chauffée, XI ${ }^{\text {ème }}$ colloque interuniversitaire Franco- Québécois sur la thermique dessystèmes pp. 1-6. 
S. Tabet

NATURAL CONVECTION IN PARTIALLY HEATED SQUARE CAVITY

S u m m a r y

Numerical investigations were led in a square cavity $(L=1)$, filled with air, of which a partially heated wall, by using a numerical code based on the finite difference method. The length of the heated part, at constant temperature, varies from $20 \%$ to $80 \%$ of the total length. The opposite vertical wall is supposed cold. The two other horizontal walls are thermically isolated. The calculation is made in laminar flow for Rayleigh number ranging from $10^{4}$ to $10^{6}$. For the validation, a preliminary calculation of the differentially heated cavity is successfully confronted with the works listed by De Vahl Davis. The outlines of temperature, the vectors speeds and the evolution of the Nusselt number are presented for various Rayleigh number while limiting itself to the laminar case.

Keywords: natural Convection, Rayleigh number, finite differences.

Received May 07, 2015

Accepted March 15, 2016 